\title{
SISTEM INFORMASI PEMESANAN FURNITURE BERBAHAN BAKU ALUMINIUM PADA USAHA DAGANG CRYSTAL ALUMINIUM MANOKWARIBERBASIS WEB
}

\author{
Sofyan ${ }^{1}$, Mardewi $^{2}$, Rikhy Ronald Moektis \\ Ilmu Komputer ${ }^{1}$ - STMIK Kreatindo Manokwari, Sistem Informasi ${ }^{2}$ - STMIK Kreatindo \\ Manokwari,Sistem Informasi ${ }^{3}$ - STMIK Kreatindo Manokwari \\ ${ }^{1} \mathrm{Jl} . K e b u n$ Cengkeh Irman Jaya Manokwari, ${ }^{2} \mathrm{Jl}$.Kebun Cengkeh Irman Jaya Manokwari \\ Email : sofyanarifin018@gmail.com ${ }^{1}, \underline{\text { mardewi0004@ } \text { gmail.com }^{2}}, \underline{\text { rikhyronal @yahoo.com }}$
}

\begin{abstract}
ABSTRAK
Sistem informasi pemesanan furniture berbahan baku alumunium berbasis web pada usaha dagang crystal aluminum" diharapkan akan dapat memberikan gambaran informasi dan transaksi pemesanan furniture berbahan almunium. Adapun Penelitian ini bertujuan untuk : (1) Merancang sebuah sistem informasi pemesanan furniture berbahan baku almunium berbasis web pada usaha dagang crystal aluminium (2) Mengimplementasikan sebuah sistem informasi pemesanan furniture berbahan baku almunium berbasis web pada usaha dagang crystal aluminum.Metode penelitian ini dilakukan dengan menggunakan metode interview, observasi dan dokumentasi. Perancangan sistem dilakukan dengan bahasa pemodelan dengan menggunakan UML(Unified Modelling Language) yang terdiri dari use case diagram, activity diagram dan sequence diagram. Sedangkan pemograman yang dipakai adalah HyperText Markup Language(HTML), Cascading Style Sheets(CSS), Hypertext Preprocessor(PHP), JQUERY, Content Management System(CMS) yang terdiri dari Wordpress dan Woocommerce dengan menggunakan database MySQL. Melakukan pengujian program dengan menggunakan metode blackbox sebagai tahap akhir dalam pembuatan aplikasi ini, dengan hasil pengujian yang bebas dari kesalahan logika.Hasil ini menunjukkan bahwa dengan adanya sistem informasi pemesanan furniture berbahan baku almunium berbasis web pada usaha dagang crystal aluminum dapat mempermudah Pemesanan dalam pemesan furniture almunium dan member untuk melihat selama ini sehingga Admin (Karyawan) dalam mengolah pemesanan dan melihat laporan transaksi. Adapun fitur yang tampil di website yaitu beranda, kategori, requist, akun saya, kotak saran dan tentang
\end{abstract}

Kata Kunci : Sistem Informasi, Web,UML.

\section{ABSTRACT}

The web-based information system for ordering furniture made of aluminum in the crystal aluminum trading business is expected to provide an overview of information and transactions for ordering furniture made from aluminum. This study aims to: (1) Design a web-based information system for ordering furniture made of aluminum for the crystal aluminum trading business (2) Implementing an information system for ordering web-based aluminum furniture in the crystal aluminum trading business.This research method is carried out by using the method of interview, observation and documentation. The system design is carried out in a modeling language using UML (Unified Modeling Language) which consists of use case diagrams, activity diagrams and sequence diagrams. While the programming used is HyperText Markup Language (HTML), Cascading Style Sheets (CSS), Hypertext Preprocessor (PHP), JQUERY, Content Management System (CMS) which consists of Wordpress and Woocommerce using the MySQL database. Performing program testing using the blackbox method as the final stage in making this application, with test results that are free from logical errors.These results indicate that the existence of a web-based information system for ordering furniture made of aluminum in the crystal aluminum trading business can facilitate ordering in aluminum furniture orderers and members to see so far so that the Admin (Employee) in processing orders and viewing transaction reports. The features that appear on the website are homepage, category, requist, my account, suggestion box and about

Keywords: Information Systems, Web, UML. 


\section{Sofyan, Mardewi dan Rikhy Ronald Moektis. Sistem Informasi Pemesanan 2020 Furniture Berbahan Baku Aluminium Pada Usaha Dagang Crystal Aluminium Manokwariberbasis WEB}

\section{PENDAHULUAN}

Saat ini peluang usaha menggunakan aluminium sangatlah besar, karena aluminium bisa di bentuk menjadi apa saja bahkan bisa menjadi berbagai produk yang dapat di hasilkan oleh logam ini termasuk juga dengan serangkaian perkakas rumah tangga. Karena perkakas rumah tangga yang terbuat dari bahan logam aluminium akan cenderung lebih praktis . Bahkan beberapa pengusaha terkenal sering memakai perkakas yang terbuat dari bahan aluminium seperti pintu lipat, lemari dan rak susun.Selain dari pencarian bahan dasar yang relatif mudah jika menggunakan logam aluminium, proses pembuatannya lebih sederhana dan cepat ketimbang menggunakan perkakas kayu. Keuntungan membuat perabot dari bahan logam aluminium ini adalah tahan dari ganguan rayap, penggemarnya yang relatif banyak dan kisaran harga yang terjangkau. Menjalankan usaha Aluminium adalah ide yang bagus dan berpotensi besar karena pada saat ini banyak sekali orang - orang yang memerlukan dan menyukai produk yang terbuat dari aluminium. Usaha aluminium juga temasuk usaha kecil menengah.

UD Crystal Aluminum adalah salah suatu usaha kerajinan pembuatan perkakas rumah tangga berbahan baku aluminium, diantara kerajinan yang di buat meliputi lemari pakaian, rak piring,rak sepatu, jemuran pakian, tangga, kursi, pintu dan lain-lain.

Awal merintis usaha kerajinan pembuatan perkakas rumah tangga berbahan aluminium di UD Crystal Aluminum modal awal kurang dari Rp. 25.000.000. sekarang aset sudah hampir mencapai Rp. 100.000.000, dengan omset rata-rata Rp. 50.000.000 hingga Rp.60.000.000 juta perbulannya, produk yang dihasilkan dari usaha kerajinan pembuatan perkakas rumah tangga berbahan aluminium ini memiliki beragam keunggulan diantaranya tahan karat, tahan rayap, kokoh dan ringan dibandingkan produk berbahan kayu. Sedangkan untuk harga, juga relatif murah yaitu dengan kisaran antara Rp. 300.000 hingga Rp. 7.000.000 per unit, tergantung model dan ukuran produk.

\section{LANDASANTEORI 2.1 Sistem Informasi}

Definisi sistem informasi adalah suatu kumpulan dari komponen-komponen dalam perusahaan atau organisasi yang berhubungan dengan proses penciptaan dan pengaliran informasi. Sistem informasi merupakan serangkaian komponen berupa manusia, prosedur, data dan teknologi (seperti komputer) yang digunakan untuk melakukan sebuah proses untuk menghasilkan informasi yang bernilai untuk pengambilan keputusan(Prasetyo \&Susanti, 2016).

\section{$2.2 \quad$ Unified Modeling Language (UML)}

Unified Modeling Language (UML) adalah bahasa spesifikasi standar yang dipergunakan untuk mendokumentasikan, menspesifikasikan dan membanngun perangkat lunak. UML merupakan metodologi dalam mengembangkan sistem berorientasi objek dan juga merupakan alat untuk mendukung pengembangan sistem](Suendri, 2018). Perancangan sistem dengan menggunakan pemodelan UML (Unified Modelling Language). UML adalah bahasa pemodelan untuk sistem atau perangkat lunak yang berparadigma (berorientasi objek)(Valfells, 1978).

\section{$2.3 \mathrm{Web}$}

World Wide Web (biasa disingkat WWW) atau web merupakan salah satu aplikasi internet yang paling popular. Web adalah sebuah sistem dimana informasi dalam bentuk teks, gambar, suara dan lainnya yang tersimpan dalam sebuah internet webserver ditampilkan dalam bentuk HTML (hypertext Markup language). Pengertian lain web atau www adalah dokumen atau informasi yang saling berhubungan yang dihubungkan melalui hyperlink atau URL(Prasetyo \& Susanti, 2016).

\section{$2.4 M y S Q L$}

MySQL adalah perangkat lunak yang tergolong sebagai DataBase Managament System (DBMS). Perangkat lunak ini bermanfaat untuk mengelola data dengan cara yang sangat fleksibel dan cepat. Berikut adalah sejumlah aktivitas yang terkait dengan data yang didukung oleh MySQL(Indrayuni et al., 2014)[5]. MySQL dapat digunakan oleh beberapa user dalam waktu yang bersamaan tanpa mengalami masalah atau konflik. Hal ini memungkinkan sebuah database server MySQL dapat diakses client secara bersamaan(Rizki et al., 2018).

\subsection{PHP}

PHP merupakan script yang menyatu dengan HTML dan berada pada server (server side HTML embedded scripting). Dengan PHP ini Anda dapat membuat beragam aplikasi berbasis web, mulai dari 


\section{Jurnal Sains Komputer dan Teknologi Informasi Page e - issn : 2655 7460. Volume 3 No.1, November 2020

halaman web yang sederhana sampai aplikasi komplek yang membutuhkan koneksi ke database(Ipnuwati, 2014)[7].PHP dirancangan untuk dapat bekerja sama dengan database server dan dibuat sedemikian rupa sehingga pembuatan dokumen HTML yang dapat mengakses database menjadi begitu mudah. Tujuan dari bahasa scripting ini adalah untuk membuat aplikasi di mana aplikasi tersebut yang dibangun oleh PHP pada umumnya akan memberikan hasilpada web browser, tetapi prosesnya secara keseluruhan dijalankan di server(Susilo, 2018).

\subsection{XAMPP}

XAMPP adalah sebuah software web server apache yang di dalamnya sudah tersedia database server MySQL dan dapat mendukung pemograman PHP(Praelsetyo \& Susanti, 2016).

\subsection{E-Commerce}

E-Commerce adalah penyebaran, pembelian, penjualan, pemasaran barang dan jasa yang dilakukan oleh konsumen melalui sistem elektronik seperti internet, WWW (World Wide Web), atau jaringan komputer lainnya. E-commerce dapat melibatkan transfer dana elektronik, pertukaran data elektronik, sistem manajemen inventori otomatis dan sistem pengumpulan data otomatis(Duan et al., 2017).

\section{METODE PENELITIAN}

\subsection{Sistem Yang Berjalan}

Sistem yang sudah berjalan pada UD Crystal Alumunium Manokwari tersebut masih bersifat manual sehingga terdapat beberapa kendala di antaranya, sulitnya Konsumen dalam pemesanan perkakas rumah tangga karena masih harus datang langsung ke UD Crystal Aluminum, Perancangan ini akan memanfaatkan teknologi informasi yang berbasis Web yang akan memebantu dalam Sistem informasi Pemesanan Furniture Berbahan Baku Aluminium Pada UD Sinar Soni Berbasis Website Berikut ini diperlihatkan melalui alur dokumen yang sedang berjalan

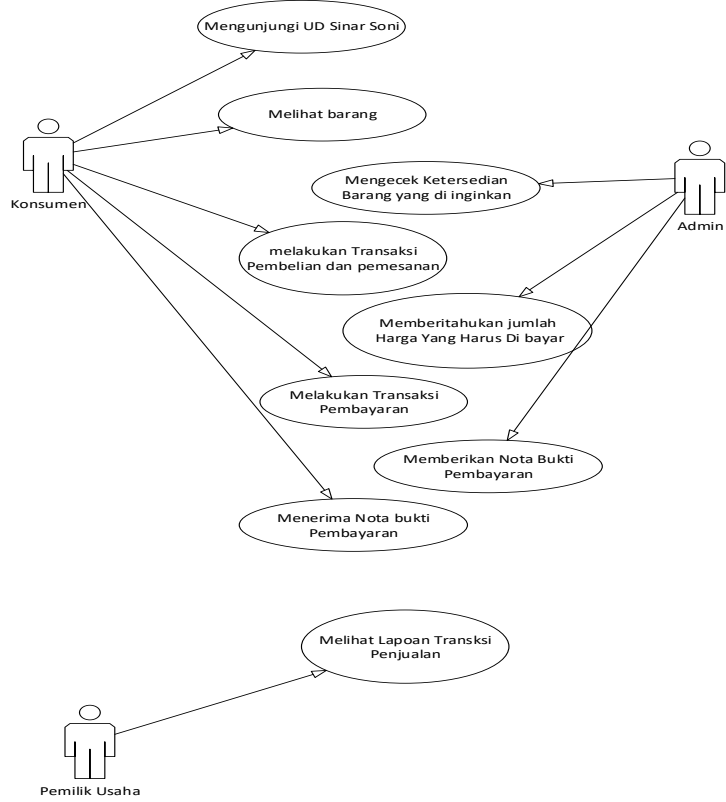

Gambar 3.1Sistem yang berjalan

Berdasarkan gambar 1 sistem yang berjalan menjelaskan bahwa terdapat 3 aktor yaitu konsumen, admin dan pemilik usaha sebagai berikut

a. Konsumen

Actor : KonsumenBrief Description

Melihat Barang, melakukan transaksi pembelian dan pemesanan, menerima nota pebayaran

Main Flow : mengunjungi UD Crystal Aluminum Manokwari, melihat barang, melakukan transaksi pembelian dan pemesanan,melakukan transaksi pembayaran, menerima nota bukti pembayaran

b. Admin

$$
\text { Actor : Admin }
$$

Brief Description :Mengecek ketersedian barang yang di inginkan, memberitahukan jumlah harga barang yang harus di bayar, memberikan nota pembayaran.

Main Flow :Melakukan pengecekan ketersedian barang yang di inginkan konsumen dan memberitahukan jumlah yang harus di bayar serta memberikan nota pembayaran

c. Pemilik Usaha

Actor : Pemilik Usaha

Brief Description: Melihat laporan transaksi penjualan Main Flow : Melakukan kegiatan pengecekan laporan kegiatan transaksi

\subsection{Sistem Yang Diusulkan}


Dari hasil evaluasi sistem yang berjalan, maka dibuatlah sistem yang di usulkan dengan harapan agar UD Crystal Alumunium Manokwari lebih mudah untuk menjual, melakukan pemesanan dan melayani pembeli dengan baik. Hasil sistem yang diusulkan

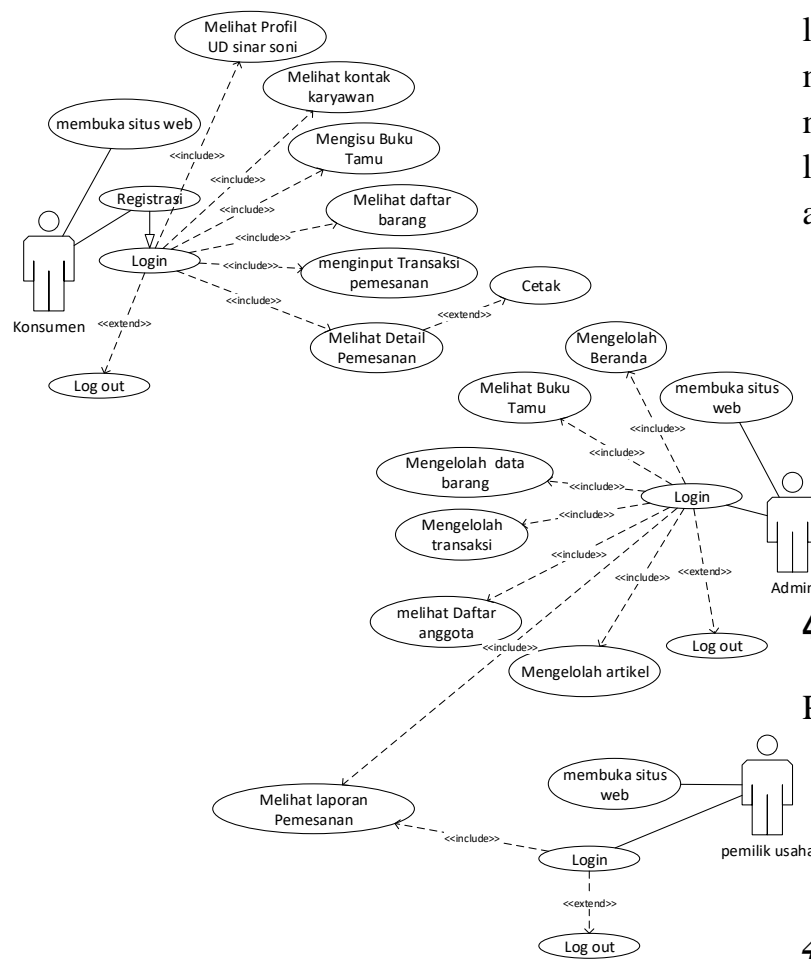

Gambar 3.2 Sistem yang diusulkanUD Crystal Aluminum

Berdasarkan gambar 2 sistem yang berjalan menjelaskan bahwa terdapat 3 aktor yaitu konsumen, admin dan pemilik usaha sebagai berikut

a. Konsumen

Actor : Konsumen

Brief Description : membuka situs web, registrasi, login, melihat profil UD sinar soni, melihat kontak karyawan, mengisi kritik dan saran, melihat barang, input pesanan, melihat detail pemesanan, cetak bukti pembayaran

Main Flow :konsumen membuka situs web, melakuan registrasi, login, melihat profil UD sinar soni, melihat kontak karyawan, mengisi kritik dan saran, melihat barang, input pesanan, melihat detail pemesanan, cetak bukti pembayaran, memperlihatkan bukti pembayaran setelah itu logout.

b. Admin

Actor : Admin
Brief Description :membuka situs web, login, mengelolah beranda, melihat kritik dan saran, mengelolah data barang, mengelolah transaksi, mengelolah artikel. Melihat daftar anggota, melihat laporan pemesanan

Main Flow : admin membuka situs web, login, lalu mengelolah beranda, melihat kritik dan saran, mengelolah data barang, mengelolah transaksi, mengelolah artikel. Melihat daftar anggota, melihat laporan pemesanan setelah itu logout.

a. Pemilik Usaha

Actor : Pemilik Usaha

Brief Description : membuka situs web, login, Melihat laporan transaksi pemesanan

Main Flow : pemilik usaha membuka situs web lalu login dan menglihat laporan transaksi pemesanan setelah itu logout.

\section{HASIL DANPEMBAHASAN}

Berdasarkan perancangan sistem informasi Pemesanan Furniture yang telah dibuat pada UD Crystal Aluminium untuk desain antarmuka, didapatkan hasil yang sejalan, berikut hasil tampilan halaman-halaman antarmuka dari aplikasi web yang dibangun:

\subsection{Halaman Utama}

pada gambar 4.1 merupakan menu utama Konsumen yang terdiri dari beberapa menu diantaranya Profil Perusahaan, Kontak, Buku Tamu, Daftar barang Registrasi dan menu login yang digunakan consumen.

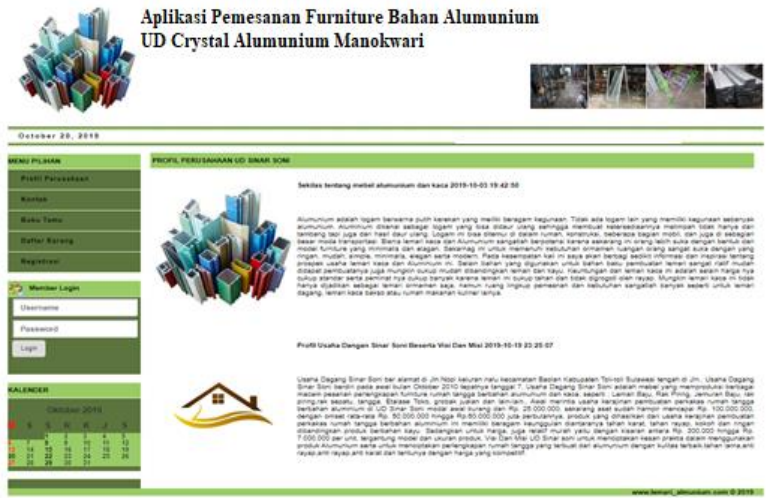

Gambar 4.1 Halaman utama

\subsection{Tampilan Menu Registrasi}

pada gambar 4.2 di atas merupakan menu 
tampilan Registrasi yang berada di tampilan menu utama Konsumen halaman ini untuk menginput biodata consumen.

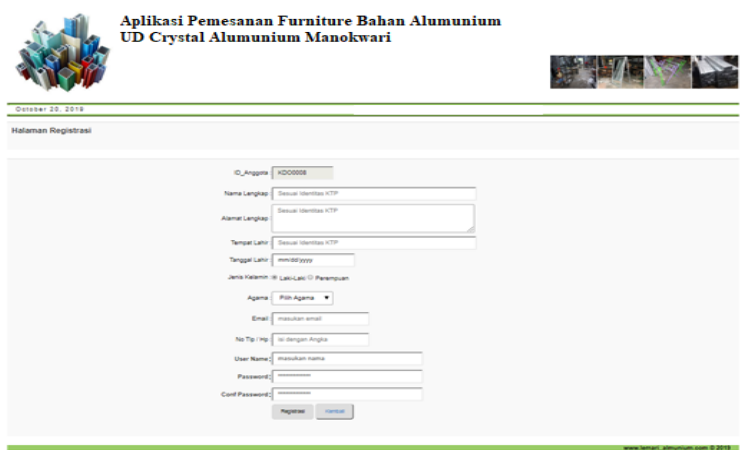

Gambar 4.2Menu Registrasi

\subsection{Daftar Barang}

pada gambar 4.3 merupakan menu tampilan daftar Barang yang berada di tampilan menu utama Konsumen dan terdapat juga fasilitas watshap untuk berkomunikasi dengan admin UD Crytal AlumuniumManokwari.

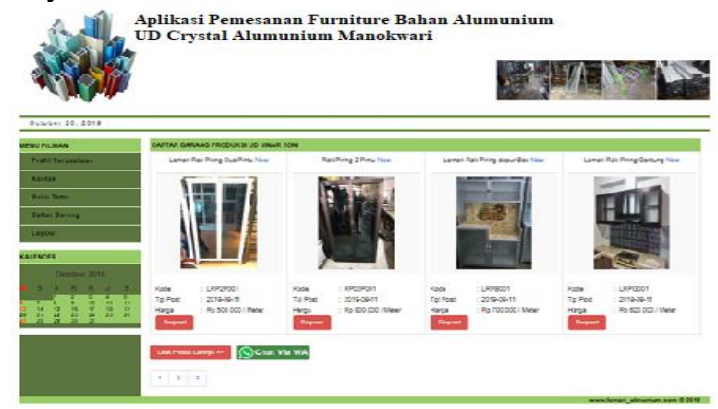

Gambar 4.3 Daftar Barang

\subsection{Tampilan Proses Pemesanan Barang}

pada gambar 4.4merupakan menu tampilan Proses Pemesanan Barang yang berada di tampilan menu utama Konsumen, Halaman ini berfungsi untuk menginput permintaan consumen.

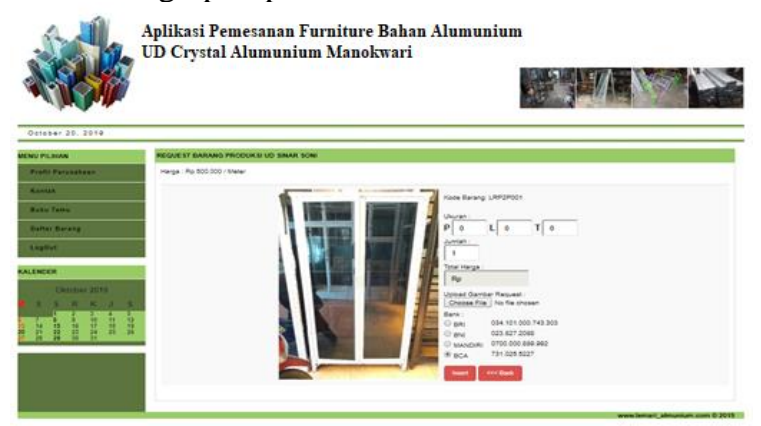

gambar 4.4 Pemesanan Barang

\subsection{Tampilan Buku Tamu}

pada gambar 4.5merupakan menu tampilan Buku Tamu yang berada di tampilan menu utama consumen halaman ini berfungsi untuk menginput komentar atau kritikan consumen terhadap Pelayanan Karyawan UD Crystal Alumunium Manokwari.

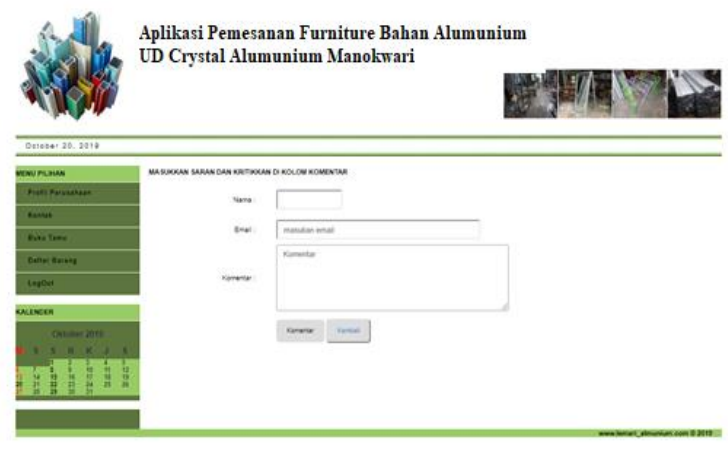

gambar 4.5Buku Tamu

\subsection{Tampilan Kontak}

pada gambar 4.5 merupakan menu tampilan Kontak yang berada di tampilan menu utama Konsumen berfungsi untuk membatu consumen berkomunikasi dengan karyawan UD Crystal Alumunium apabila ada kesalahan pemesanan.

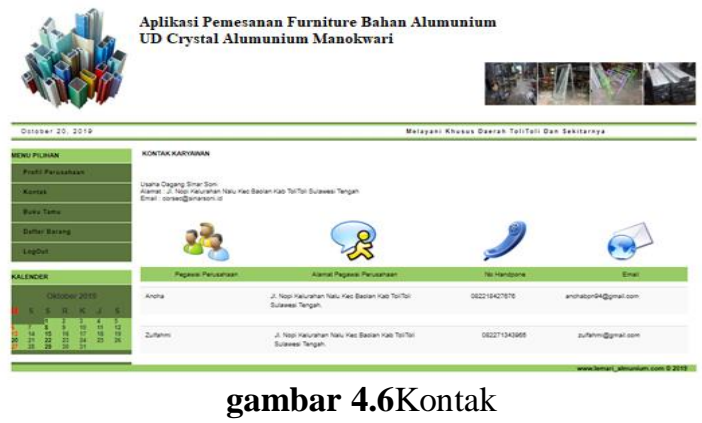

\section{KESIMPULAN DANSARAN \\ 5.1 Kesimpulan}

Berdasarkan hasil observasi dan uraian pada bab sebelumnya, maka dapat ditarik kesimpulan sebagai berikut:

1. Pada sistem informasi pemesana furniture berbahan baku almunium pada UD Crystal Alumunium Manokwariberbasis ini menyajikan informasi mengenai kebutuhan rumah tangga yang tersedia yang diperjualkan.

2. Dengan adanya website ini masyarakat dapat melihat dan melakukan transaksi pemesanan untuk produk furniture yang diinginkan tanpa harus mengunjungi Perusahaan dan perlu komunikasi melalui media sosial dan telpon seluler untuk pemesanan tersebut.

\subsection{Saran}

Berdasarkan kesimpulan yang diperoleh, diajukan beberapa saran sebagai berikut:

1. Kiranya pada UD Crystal Alumunium Manokwari dapat menerapkan webiste ini untuk pelayanan yang 


\section{Sofyan, Mardewi dan Rikhy Ronald Moektis. Sistem Informasi Pemesanan Furniture Berbahan Baku Aluminium Pada Usaha Dagang Crystal Aluminium Manokwariberbasis WEB}

prima dan benefit perusahaan yang semakin meningkat.

2. Sistem ini dapat mempermudah pekerjaan, maka diharapkan bagi Pemilik Toko (admin) memahami sistem kerja website ini sehingga dapat menghindari kesalahan atau kekeliruan dan penginputan data.

\section{DAFTAR PUSTAKA}

Duan, J., Hu, H., Zhang, Y., Feng, L., Shi, Y., Miller, M. R., \& Sun, Z. (2017). Multi-organ toxicity induced by fine particulate matter PM2.5 in zebrafish (Danio rerio) model. Chemosphere, 180(1), 24-32. https://doi.org/10.1016/j.chemosphere.2017.04. 013

Indrayuni, E., Nurhadi, A., \& Sinnun, A. (2014). Rancang Bangun Sistem Informasi Perpustakaan Berbasis Web. Konferensi Nasional Ilmu Sosial Dan Teknologi, 1(1), 7885.

Ipnuwati, S. (2014). Perancangan Sistem Informasi Penjualan Pada Toko Minak Singa. Explore: Jurnal Sistem Informasi Dan Telematika, 4(2), 12-20. https://doi.org/10.36448/jsit.v4i2.536

Praelsetyo, A., \& Susanti, R. (2016). Sistem Informasi Penjualan Berbasis Web Pada PT.
Cahaya. Jurnal Ilmiah Teknologi Informasi Asia, 10(2), 1-16.

Prasetyo, A., \& Susanti, R. (2016). Sistem Informasi Penjualan Berbasis Web Pada PT. Cahaya Sejahtera Sentosa Blitar. Jurnal Ilmiah Teknologi Informasi Asia, 10(2), 1-16.

Rizki, I., Raden, A. S. P., \& Yuniati, Y. (2018). Pembuatan Sistem Informasi Penjualan Berbasis Web ( Studi Kasus pada Toko Ali Computer ). Jurnal Rekayasa Dan Teknologi Elektro, 8(1), 37-44.

Suendri. (2018). Implementasi Diagram UML (Unified Modelling Language) Pada Perancangan Sistem Informasi Remunerasi Dosen Dengan Database Oracle (Studi Kasus: UIN Sumatera Utara Medan). Jurnal Ilmu Komputer Dan Informatika, 3(1), 1-9. http://jurnal.uinsu.ac.id/index.php/algoritma/arti cle/download/3148/1871

Susilo, M. (2018). Rancang Bangun Website Toko Online Menggunakan Metode Waterfall. InfoTekJar (Jurnal Nasional Informatika Dan Teknologi Jaringan), 2(2), 98-105. https://doi.org/10.30743/infotekjar.v2i2.171

Valfells, A. (1978). Economics of Upgrading Geothermal Steam By Adiabatic Compression. $v(6), 2827-2839$. 